\title{
DETERMINATION OF APPROPRIATE EXPOSURE TO FLUORIDE IN NON-EME COUNTRIES IN THE FUTURE
}

\author{
DETERMINAÇÃO DA EXPOSIÇÃO APROPRIADA A FLUORETO NO FUTURO \\ PARA PAÍSES DE ECONOMIA DE MERCADO NÃO ESTABILIZADA
}

\author{
Jaime Aparecido CURY \\ Professor, FOP-UNICAMP. \\ Cínthia Pereira Machado TABCHOURY \\ Assistant Professor, FOP-UNICAMP.
}

Presented by the first author in "Workshop: Opportunities for International Research on Fluoride", National Institute of Dental and Craniofacial Research, Bethesda, Maryland, USA, May 10-12, 1999 (the references originally cited were updated)

\begin{abstract}
$A$ $\mathrm{n}$ appropriate exposure to fluoride must be able to interfere with the development of dental caries (benefit) without great concern for dental fluorosis (risks). This condition in relation to individual seems feasible leading to a rational use of fluoride. Nevertheless, dealing with population and particularly non-EME countries (nonEstablished Market Economies or developing), the most suitable method of fluoride use will depend on each nation. On the other hand, each country should have a public health program to control dental caries as part of its health system. The choice between fluoridated dentifrice or fluoridated drinking water and the option for salt will depend on its applicability in each country. At the same time, it is important that either the appropriate exposure to a community method of fluoride use as well as the association with other methods and preventive measures in relation to risks-benefits are evaluated for each country. The determination of an appropriate exposure to fluoride in non-EME countries in the future will depend on critical analysis of how it has been used at present. Available data have shown that some non-EME countries have even been able to revert the dramatic situation of dental caries in their population, but in others caries experience continues a public health problem. Nevertheless, in other countries the increase in caries prevalence, which was expected, has not occurred but endemic fluorosis has been a concern. The challenges for non-EME countries are huge and identical solutions cannot be used for distinct problems.
\end{abstract}

UNITERMS: Fluoride; Fluorosis; Dental caries, risks/benefits.

\section{INTRODUCTION}

An appropriate exposure to fluoride is the one able to interfere with the development of dental caries (benefit) without great concern for dental fluorosis (risks). The determination of the most adequate measure in the future for non-EME (non-Established Market Economies or developing) countries must be based on data from the present in terms of dental caries and dental fluorosis prevalence, so that rational suggestions can be done. The discussion should also rely on results of programs implemented in different countries, either in their successes or, mainly, the difficulties faced.
To accomplish this hard mission, about this subject, the difficulties are enormous due to: a) Heterogeneity of non-EME countries; b) Scarce publications in worldwide literature for a critical evaluation and, mainly; c) The risk of being a personal opinion.

The data of dental caries and fluorosis prevalence will be analyzed. Further, the methods of fluoride use will be evaluated discussing whether they would be appropriate in the future and suggestions for changes and research will be made.

\section{Dental caries in non-EME countries}

Fortunately, it seems that the predictions of drastic 
dental caries increase in non-EME countries did not become true ${ }^{19}$. Analyzing the data from $\mathrm{WHO}^{59}$ per region: Africa (AFRO), Eastern Mediterranean (EMRO), Southeast Asia (SEARO), Americas (AMROS), Europe (EURO) and Western Pacific (WPRO), we can observe that the situation is more serious in regions like Americas and Europe (Table 1).

Thus, more than $50 \%$ of the non-EME countries in these regions show moderate to very high caries prevalence. On the other hand, $86 \%$ of African countries and $82 \%$ of Asian countries show low to very low caries prevalence. Even though these data may be subjected to critics, they are what we have and may be useful.

In this way, an increase in caries prevalence is expected when the primitive diet in a country is changed for a western one containing sucrose. This increase in dental caries is predictable since sugar offer precedes the establishment of habits to control dental plaque and fluoride use. Sucrose shows a unique characteristic to induce quali-quantitative changes in dental plaque formation, making it more cariogenic than the one formed in the presence of its forming monosaccharides (Table 2).

Table 2 shows that sucrose increases the amount of plaque formed, which contains a low inorganic concentration $\left(\mathrm{Ca} \times \mathrm{P}_{i} \times \mathrm{F}\right)$ and a high concentration of insoluble polysaccharide (IP). Dental plaque formed in the presence of sucrose was more cariogenic and enamel mineral loss was visible ("white spot"), which was quantified by surface microhardness change (SMHC\%). This in situ study confirms that sucrose induces drastic changes in the oral environment and a clinical study showed similar results (Table 3 ).

The results showed in Tables 2 and 3 were obtained from individuals drinking fluoridated water and a low

TABLE 1- Percentage of countries according to $\mathrm{DMFT}_{12}$ and region

\begin{tabular}{|c|c|c|c|c|c|c|}
\hline \multirow{2}{*}{ REGIONS } & \multicolumn{6}{|c|}{ CARIES PREVALENCE } \\
\hline & VL & $\mathbf{L}$ & $\mathbf{M}$ & $\mathbf{H}$ & VH & $\mathbf{n}$ \\
\hline AFRO & 44 & 42 & 11 & 3 & 0 & 36 \\
\hline EMRO & 24 & 57 & 14 & 5 & 0 & 21 \\
\hline SEARO & 9 & 73 & 8 & 0 & 0 & 11 \\
\hline AMRO & 3 & 23 & 34 & 31 & 9 & 35 \\
\hline EURO & 0 & 43 & 39 & 18 & 0 & 28 \\
\hline WPRO & 4 & 65 & 22 & 9 & 0 & 23 \\
\hline
\end{tabular}

VL-very low; L-low; M-medium; H-high; VH-very high.

TABLE 2- Composition of dental plaque according to the of treatments

\begin{tabular}{|c|c|c|c|}
\hline \multirow[t]{2}{*}{ ANALYSIS } & \multicolumn{3}{|c|}{ TREATMENTS } \\
\hline & CONTROL & Glucose+Fructose & SUCROSE \\
\hline Wet weight (mg) & $4.5 \pm 2.2^{\mathrm{a}}$ & $7.3 \pm 1.2^{\mathrm{a}}$ & $13.2 \pm 2.1^{b}$ \\
\hline$F(\mu g / g)$ & $46.1 \pm 8.4^{a}$ & $9.3 \pm 5.4^{b}$ & $3.7 \pm 1.0^{b}$ \\
\hline$P_{i}(m g / g)$ & $11.5 \pm 2.08^{a}$ & $0.5 \pm 0.14^{b}$ & $0.3 \pm 0.04 b$ \\
\hline $\mathrm{Ca}(\mathrm{mg} / \mathrm{g})$ & $17.0 \pm 2.75^{a}$ & $1.9 \pm 0.69 b$ & $0.6 \pm 0.08^{b}$ \\
\hline IP (mg/g) & $6.5 \pm 1.0^{a}$ & $11.8 \pm 1.9^{a}$ & $35.0 \pm 7.8^{b}$ \\
\hline “White spot”(\%) & 0 & 56 & 90 \\
\hline SMHC (\%) & $3.3 \pm 0.7^{a}$ & $44.2 \pm 7.2^{b}$ & $73.4 \pm 6.9^{c}$ \\
\hline
\end{tabular}

Means followed by distinct superscript letters show difference among treatments $(p<0.05)$.

IP-Insoluble polysaccharide; SMHC-surface microhardness change 
fluoride concentration was found in dental plaque formed in situ in presence of sucrose or in children ingesting more sugar and presenting high activity of caries $^{17,41}$

On the other hand, it is possible that depending on the culture and economy of each country there is a great resistance to a change in diet. In this way, low caries prevalence in most of the African and Asian nations would probably be due to their strong attachment to millenary cultures with low sugar consumption. Nevertheless, the American continent has practically no preserved culture. Because their population descended from a racial mixture, there are no traditions to be preserved and they are vulnerable to changes. Furthermore, due to several problems related to economy and politics only after chaos occurs in oral health, measures would start to be taken and most of the times they try to minimize the problem but not to solve it. On the other side, even though an increase in caries prevalence in countries from Africa and China did not occur, two aspects must be evaluated ${ }^{19}$. The first one is that much of the caries experience is accounted for a relatively small proportion of individuals. The second is that children from a higher socio-economic level show a higher caries prevalence. This seems to be an alert for a possible repetition of caries history, which occurred in western countries, and its disastrous consequences for a population of lower social-economic level, who will not benefit from the same preventive measures to control it.

Although reduction in sugar consumption seems to be the most evident solution for the caries problem, from a public point of view its success has been limited. Among the solutions for the problem, the use of fluoride has been one of the preventive measures with the highest impact on caries control. It has been used in most of non-EME countries and significant results of caries reduction have been observed. On the other hand, when it is used alone it is efficient to reduce caries, but caries prevalence only changes from a very high level to a moderate one. Therefore, to increase its efficacy and to reach a low caries prevalence, oral health education aiming the control of dental plaque through brushing is necessary. There is evidence to support this observation in non-EME countries ${ }^{16}$.

\section{Dental Fluorosis in non-EME Countries}

Dental fluorosis in non-EME countries is either endemic or due to methods of fluoride use. Natural fluoride in water has been reported in most of nonEME countries. In addition, the prevalence of dental fluorosis in many countries is higher than expected considering the concentration of fluoride in water. This fact is attributed to the hot climate in Senegal ${ }^{7}$; Kenia, Sri Lanka ${ }^{2} ;$ Sudan $^{30}$ and Jordan ${ }^{23}$. Regional habits such as the use of magadi salt in Tanzania ${ }^{60}$ and tea in China are also factors that explain the high prevalence of dental fluorosis. Environmental pollution in $\mathrm{China}^{57}$ and Morocco $^{1}$ is also related to the increase of dental fluorosis prevalence.

Studies in South and Central America on dental fluorosis have also been reported. In Costa Rica the ingestion of water containing a concentration of 0.8$1.4 \mathrm{ppm} \mathrm{F}$ is a public health concern due to the severity of dental fluorosis ${ }^{50}$. Evaluation conducted in Chile in regions with fluoridated water ranging from 0.07 to $1.1 \mathrm{ppm} F$ have suggested that the optimum concentration for that country would be $0.5-0.6 \mathrm{ppm}$ $\mathrm{F}$ and not $1.0 \mathrm{ppm}^{54}$. In Brazil, fluorosis prevalence has been evaluated more regularly in the last years.

TABLE 3- Dental plaque composition and caries in primary dentition

GROUPS / CARIES PATTERN

\begin{tabular}{|c|c|c|c|}
\hline ANALYSIS & FREE & OCCLUSAL & BOTTLE \\
\hline dmfs & 0 & $2.4^{a}$ & $5.6^{b}$ \\
\hline$F(\mu g / g)$ & $30.2^{a}$ & $16.6^{b}$ & $4.0^{\circ}$ \\
\hline$P_{i}(m g / g)$ & $6.1^{\mathrm{a}}$ & $4.0^{b}$ & $2.6^{b}$ \\
\hline $\mathrm{Ca}(\mathrm{mg} / \mathrm{g})$ & $10.6^{a}$ & $7.9^{a}$ & $3.3^{b}$ \\
\hline $\mathrm{IP}(\mathrm{mg} / \mathrm{g})$ & $39.2^{a}$ & $47.4^{\mathrm{b}}$ & $55.6^{b}$ \\
\hline Sugar exposure/day & $2.9^{a}$ & $3.9^{b}$ & $5.3^{c}$ \\
\hline S.mutans-log CFU/mg & $8.6^{a}$ & $11.3^{b}$ & $14.3^{b}$ \\
\hline
\end{tabular}

Means followed by distinct superscript letters show difference between groups $(p<0.05)$.

dmfs-decayed, missing and filled surfaces; IP- insoluble polysaccharide; CFU-colony forming-unit. 
Natural fluoride in water is largely spread in Brazil making it hard to predict where fluoride would not be found (Table 4).

Concentrations in water from 0.01 to $10.5 \mathrm{ppm} \mathrm{F}$ have been found and a survey showed severe dental fluorosis, in almost $50 \%$ of children, when water containing $4.25 \mathrm{ppm} \mathrm{F}$ was drunk ${ }^{43}$. At present, the problem is that more and deeper wells are being drilled in order to obtain potable water and most of the times a high concentration of fluoride is found, but this is the only available source of water. Nevertheless, there are two available studies in Brazil on fluoride concentration in water and dental fluorosis (Table 5).

The difference between the studies can be explained because the ambient temperature is higher in the cities of the states of Espírito Santo (ES) and Ceará (CE) than São Paulo (SP).

On the other side, concomitant with surveys showing caries reduction in Brazil a concern about dental fluorosis started to arise. Even though there is no description about it, there is evidence of an increased prevalence in cities containing or not fluoridated water (Table 6) ${ }^{46}$.

These data showed a higher prevalence of very mild dental fluorosis and other surveys in Brazil have found that the prevalence is higher in children from private schools. In relation to this prevalence of dental fluorosis, there is a division of opinions in Brazil among the dental professionals. Even though the majority considers that the prevalence is not a public health problem and is in agreement with the perception of the population ${ }^{4,10}$, the range of dose to which children are submitted is very wide ${ }^{44}$.

Thus, Table 7 shows that, in terms of mean, the risk would be a clinically acceptable dental fluorosis in the population, but the variability is extremely concerning in terms of individual ${ }^{44}$. It must be clarified that the data obtained in this study are related to total fluoride ingested from diet or dentifrice and not that absorbed, so the risk is, in fact, lower. On the other

TABLE 4- Natural fluoride in water in some Brazilian cities (from 1500 samples)

\begin{tabular}{lllll}
\hline CITY & STATE & REGION & YEAR & ppm F \\
\hline Godinhos & SP & SE & 1980 & 2.40 \\
Corumbataí & SP & SE & 1984 & 10.20 \\
Assistência & SP & SE & 1986 & 2.00 \\
Cocal & SC & S & 1987 & 4.25 \\
Castro & PR & S & 1990 & 1.50 \\
Miracema & TO & N & 1991 & 4.58 \\
Grossos & RN & NE & 1991 & 0.49 \\
Santa Cruz & RN & NE & 1991 & 0.90 \\
Attântida & RS & S & 1991 & 1.91 \\
Itu (farm) & SP & SE & 1998 & 7.30 \\
\hline
\end{tabular}

In: Cury ${ }^{16} ; 2001$

TABLE 5- Dental fluorosis prevalence (TF-index) according to fluoride concentration in water

\begin{tabular}{lll}
\hline CITY, State & ppm F & \% Children \\
\hline${ }^{1}$ Iracemápolis, SP & $<0.02$ & 4.2 \\
${ }^{1}$ Piracicaba, SP & $0.7(0.6-0.8)$ & 17.6 \\
${ }^{1}$ Cesario Lange, SP & 1.4 & 33.7 \\
${ }^{2}$ Maceió, AL & $<0.01$ & 7.5 \\
${ }^{2}$ Grande Vitória, ES & $0.7(0.54-0.96)$ & 52.2 \\
${ }^{2}$ Olho D'Agua, CE & $2-3$ & 81.7 \\
\hline
\end{tabular}

${ }^{1}$ Pereira, Moreira; $1999^{47} ;{ }^{2}$ Ellwood, et al.; $1996^{18}$ hand, it is better to overestimate than to underestimate any risk when we are dealing with toxicology. These data are relevant even though $0.07 \mathrm{mg} \mathrm{F} / \mathrm{Kg}$ body weight/day, which is considered the upper limit for fluoride intake in children ${ }^{8}$, was not evaluated by longitudinal studies.

\section{Community Programs of Fluoride Use}

\section{1- Fluoridated Drinking Water}

The success of this method in relation to reduction of dental caries prevalence was also proved in non- 
EME countries. Table 8 shows DMFT of 12 -year-old children in Brazilian cities as a function of time after water fluoridation ${ }^{3}$.

The data from Table 8 and many other studies show that the prevalence of dental caries in Brazil was very high before water fluoridation and decreased reaching a moderate prevalence in the nineties. This fact shows the strength of the method alone leading to a reduction of $50 \%$ in caries prevalence. On the other hand, it is possible to observe that after the nineties the reduction in caries prevalence was rapid reaching, in 1995, values that are similar to those from EME countries. Several factors may have contributed for this sharp caries decline: 1) Before September 1988 approximately $25 \%$ of toothpaste sold contained fluoride, which increased to $90 \%$ because the most popular Brazilian dentifrice was fluoridated ${ }^{13}$. Now all toothpastes sold in Brazil are fluoridated; 2) Implementation of educational and preventive programs in several public schools with distribution

TABLE 6- Prevalence of dental fluorosis (TF-index) according to water fluoridation and time

\begin{tabular}{lllllll}
\hline CITY & \multirow{2}{*}{$\mathrm{H}_{2} \mathrm{OF}$} & \multicolumn{5}{c}{ YEAR } \\
\cline { 3 - 7 } & & $\mathbf{1 9 9 1}$ & $\mathbf{1 9 9 5}$ & $\mathbf{1 9 9 6}$ & $\mathbf{1 9 9 7}$ & AGE \\
\hline Iracemápolis, SP & $<0.02$ & 2.0 & 4.2 & - & 10.1 & $11-13$ \\
Piracicaba, SP & 0.70 & 20.4 & 17.6 & - & 31 & $11-13$ \\
\hline
\end{tabular}

Pereira et al, $2001^{46}$

TABLE 7- Fluoride dose to which Brazilian children are exposed, mean \pm SD (range)

$\mathrm{mg} \mathrm{F/} \mathrm{kg} \mathrm{body} \mathrm{weight/} \mathrm{day}$

\begin{tabular}{llll}
\hline Community & \multicolumn{1}{c}{ Diet } & Dentifrice & Combined \\
\hline Ibiá & & & $0.088 \pm 0.049^{\mathrm{A}}$ \\
$(\mathrm{n}=32)$ & $0.027 \pm 0.013^{\mathrm{A}, \mathrm{a}}$ & $0.061 \pm 0.045^{\mathrm{A}, \mathrm{b}}$ & $(0.035-0.212)$ \\
& $(0.007-0.072)$ & $(0.011-0.181)$ & $0.090 \pm 0.022^{\mathrm{A}}$ \\
Piracicaba & & & $(0.057-0.162)$ \\
$(\mathrm{n}=39)$ & $0.040 \pm 0.009^{\mathrm{B}, \mathrm{a}}$ & $0.052 \pm 0.019^{\mathrm{A}, \mathrm{b}}$ & $(0.027-0.114)$ \\
& $(0.024-0.063)$ & & \\
\hline
\end{tabular}

Means followed by distinct letters differ statistically $(p<0.05)$. Capital letters show difference between communities and small letters, between diet and dentifrice.

TABLE 8- Caries prevalence (DMFT) in 12-year-old children after water fluoridation

\begin{tabular}{llllllllllllll}
\hline & \multicolumn{10}{c}{ YEAR } \\
CITIES & H OF & $\mathbf{7 1}$ & $\mathbf{7 5}$ & $\mathbf{7 7}$ & $\mathbf{8 0}$ & $\mathbf{8 1}$ & $\mathbf{8 9}$ & $\mathbf{9 2}$ & $\mathbf{9 3}$ & $\mathbf{9 4}$ & $\mathbf{9 5}$ & $\mathbf{9 6}$ & $\mathbf{9 7}$ \\
\hline Curitiba, PR & 1958 & - & - & - & - & 10.1 & 6.0 & - & 3.5 & - & - & 2.2 & 1.8 \\
Piracicaba, SP & 1971 & 8.6 & - & 7.4 & 6.2 & - & - & 3.5 & - & - & - & - & 2.2 \\
Paulínia, SP & 1980 & - & - & - & 8.2 & - & - & - & - & 3.0 & - & 2.1 & - \\
Santos, SP & 1983 & - & 8.9 & - & - & - & 5.1 & - & 3.5 & - & 1.7 & - & - \\
\hline
\end{tabular}


of toothpaste and toothbrush every three months.

The conditions for implementation are the great problem in water fluoridation. Thus, in Brazil it was expanded in the south and southeast regions, but in the north and northeast region, where the population needs it more, water fluoridation is insufficient even in the capitals. Another problem of water fluoridation is the control of fluoride concentration in terms of risks/benefits, but there was a great advance in Brazil after 1988. In São Paulo, the state government is responsible for the water treatment, but the Department of Health of the city of São Paulo started to monitor the fluoride concentration in water network. This initiative was followed by other cities and an independent control has been implemented. So, for example in Santos, SP, when the system was implanted in 1990 only $61 \%$ of the samples showed optimum concentration (0.6-0.8 ppm F). In 1991, 1992, 1993 and 1994 this number reached the values of, respectively, 68, 94, 100 and $96 \%$ of samples of network with optimum concentration ${ }^{33}$.

In Brazil, water fluoridation is a public health measure officially implemented by law since 1975 and even though it has showed efficacy to reduce dental caries prevalence, its coverage is approximately $40 \%$ of Brazilian population. The capacity of this method to reduce dental caries has been proved in other nonEME countries, such as Cuba, where very high caries prevalence was reduced to moderate ${ }^{48}$.

\section{2- Fluoridated Salt}

This method has been emphatically suggested by the Panamerican Health Organization (PAHO) as an ideal option for water fluoridation in non-EME countries in the Americas. The success of salt fluoridation in Switzerland and a pilot study conducted in Colombia have been the reference for its implementation, which in my opinion should be faced with skepticism.

Thus, in 1990, there was an attempt to implement a program of salt fluoridation in Brazil, arguing that it would be efficient and would reach more areas such as north-northeast region, which are not favored by water fluoridation. The dealers of fluoride, interested in the program, conducted a test in Rio Grande do Norte, the greates salt producer in Brazil, evaluating a technique to fluoridated the salt. This attempt was followed by a consultant of the Health Ministry, who wrote a technical, whose main observations were:

1) In the north-northeast part of the country, approximately $50 \%$ of the salt consumed cannot be fluoridated to an optimum estimated concentration
(250.0 $\mathrm{mg} \mathrm{F} / \mathrm{Kg}$ ), because they are not refined. Considering that this salt is used by people from the lowest socioeconomic status, the method would not have social impact;

2) In the north-northeast region, there is natural fluoride in water at an optimum concentration for that area $^{15}$, which would inevitably lead to an overdose in terms of dental fluorosis, which was later described in Paraiba state ${ }^{51}$;

3) Fluoride potassium, which is added to the salt, would be sold to the government as a $20 \%$ solution and would be transported from producers located in São Paulo, Rio de Janeiro and Santa Catarina to the northeast region. It is inconceivable to pay to transport $80 \%$ of water and to the same companies, which already monopolize sales of iodine to the federal government;

4) Fluoride concentration in salt should be 250.0 $\mathrm{mg} \mathrm{F} / \mathrm{kg}$ considering the national consumption of 10 $15 \mathrm{~g}$ salt/day. As Brazil is a continental country, the real consumption depends on feeding habits from each region. This fact was proved 05 years earlier ${ }^{53}$ when urinary excretion of fluoride was determined in children from Piracicaba ingesting meals prepared with fluoridated salt or consuming fluoridated drinking water. The excretion from salt was $25 \%$ lower than that from water. Then, the concentration in salt should be $300.0 \mathrm{mg} \mathrm{F} / \mathrm{kg}$ in order to maintain the same metabolic level of fluoridated water.

Additionally, it must be pointed out that policy alterations due to the implementation of democracy in non-EME countries limit the imposition of preventive measures and programs. Thus, besides the technical report ${ }^{15}$ and a review restraining the program of salt fluoridation in Brazill ${ }^{52}$, there was a political one produced in the Oral Health Department in the state of São Paulo ${ }^{39}$. The solutions for a nation are most of the times decided by others; a recent publication $^{11}$ reports that the program of salt fluoridation is being conducted in Brazil.

On the other hand, the program of salt fluoridation was successfully implemented in some countries. Results of significant caries reduction have been reported in Costa Rica $^{49}$, although it is interesting to study two aspects: a) Impact of the program in social terms; b) Prevalence of dental fluorosis. However, the concentration of fluoride in salt produced by 3 companies in Costa Rica is in accordance with what is expected ${ }^{25}$, in Mexico it is below the value established by law ${ }^{35}$. Additionally, recent publication has suggested that the caries decline found in Jamaica may not be attributed to the program of salt fluoridation implemented in that country ${ }^{36}$. 


\section{3- Fluoridated Dentifrice}

Fluoridated dentifrice has been considered by experts as the main reason for the caries decline in EME countries, which has produced an exciting debate ${ }^{6}$. The explanation is the timing between the increase of fluoridated toothpaste participation in the market and the caries decline in 16 countries. In non-EME countries and particularly in Brazil, it seems that the same trend happened after 1990. This has been shown in a longitudinal study ${ }^{46}$ and there is evidence in national level ${ }^{28}$. Thus, Table 9 shows the caries prevalence reduction (DMFT) in children (11-13 years old) in one Brazilian city independent of water fluoridation ${ }^{45}$.

Therefore the difference in dental caries prevalence between the cities, which was 50\% in 1991, was reduced to approximately $20 \%$ in the following years. The fact that more than $90 \%$ of the Brazilian toothpastes started to be fluoridated in 1989 suggests that they can have contributed for caries reduction. On the other hand, at the same time preventive and educative programs were implemented in both cities. Besides involving oral hygiene and weekly fluoride rinses, each child received from the city government a toothbrush and a fluoridated dentifrice every three months. In addition, it must be pointed out that in Brazil changes in the philosophy to treat dental caries had started to consolidate.

In Brazil, a survey conducted in the capitals of five Brazilian regions confirmed the tendency for a caries decline in non-EME countries too. Table 10 shows the reduction in DMFT index in children aged 12 years old in Brazil.

These data suggest that fluoridated dentifrice contributed to this caries decline, but at the same time it shows that a lower dental caries prevalence in the southeast and south regions is due to water fluoridation and a concomitant implementation of preventive programs, which are well organized in these places. It is important to notice that a caries reduction has also been observed in children from private school, where there is no oral health program implemented.

TABLE 9- Caries prevalence reduction as a function of time according to water fluoridation $\left(\mathrm{H}_{2} \mathrm{O} \mathrm{F}\right)$ or not

\begin{tabular}{lcccc}
\hline & \multicolumn{5}{c}{ YEAR } \\
CITIES & $\mathrm{H}_{2}$ O F & 1991 & 1995 & 1997 \\
\hline Piracicaba, SP & 1971 & 3.4 & 2.7 & 2.2 \\
Iracemápolis, SP & - & 6.8 & 3.9 & 2.9 \\
\hline
\end{tabular}

On the other hand, there is not a study design to evaluate the direct effect of fluoridated dentifrice in nonEME countries. Factors such as the cost of dentifrice and toothbrush are limiting in non-EME countries. In Brazil, the population at school with low socioeconomic status started to receive dentifrice and toothbrush through preventive and educational programs. With changes in the health system in Brazil since 1989, the cities started to be responsible for their health program. The federal government paid monthly for a child in the program and the government of the city was responsible for the toothbrush and fluoridated dentifrice supplied to the student every three months. The industries had to produce toothbrushes and toothpastes with competitive prices, because the government of the cities bought them from the cheapest producer. At the same time that in vitro and in situ studies showed that Brazilian fluoridated dentifrices had quality to interfere with dental caries ${ }^{14}$, the consumption per capita increased $40 \%$ in the last 10 years. At present, Brazil is the third country in the world related to dentifrice consumption ( $1.4 \mathrm{~g} /$ day/person), behind only the United States and Japan. The four dentifrices, which lead the sales ( $80 \%$ of total), use calcium carbonate as abrasive, which is abundant in the country. The challenge for the non-EME countries is to produce a dentifrice with low cost in order to be affordable for the population using local resources. In Brazil, a 90-g fluoridated toothpaste can cost 0.5 dollar.

Although it is believed that the caries decline in EME countries may be attributed to the widespread fluoride use, a study showed that between 1983-1989 there was a caries decline in Dar es Salaam (Tanzania), where fluoride is not widely used ${ }^{38}$. However, in this city caries prevalence was very low.

TABLE 10- Prevalence and reduction of dental caries in Brazil after 10 years

\begin{tabular}{lllll}
\hline & & \multicolumn{3}{c}{ DIFFERENCE } \\
REGIONS & H $_{\mathbf{2}}$ OF $^{*}$ & 1986 & 1996 & $\mathbf{( \% )}$ \\
\hline North & - & 7.50 & 3.52 & 53.1 \\
Northeast & - & 6.90 & 3.13 & 54.6 \\
Centerwest & $+/-$ & 8.53 & 2.82 & 66.9 \\
Southeast & + & 5.95 & 2.34 & 60.7 \\
South & + & 6.31 & 2.41 & 61.8 \\
Brazil & $+/-$ & 7.04 & 2.84 & 59.6 \\
\hline
\end{tabular}

Most of the cities are: non-fluoridated (-), fluoridated (+) and almost $50 \%$ are fluoridated (+/-) 


\section{DISCUSSION}

In the past, the most appropriate use of fluoride for populations of different countries was extensively discussed. The objective was to reduce dental caries prevalence as a health public problem. Nevertheless, knowing that most of the times the decline of dental caries occurred simultaneously with the increase of dental fluorosis prevalence, at the present time the question is whether it is possible in the future to have practically no caries and little concern for dental fluorosis.

Thus, the present question is the appropriate exposure to fluoride able to interfere with the development of dental caries without concern for dental fluorosis. The objective is to guarantee that we can still make good use from the benefits of fluoride without jeopardizing its appropriate use. This is relevant, because if resistance to fluoride use in terms of general health was a problem in the past and dental fluorosis was considered acceptable, in the future the slogan "it is better dental fluorosis than severe caries" - will be surely outdated.

In addition, in the past fluoride ingestion during the formation of teeth was considered indispensable for a resistance to dental caries and in this way dental fluorosis would be an acceptable consequence. Nevertheless, at present it is recognized that dental caries can be controlled by fluoride use without a need to ingest it.

On the other hand, for many countries in terms of public health the most appropriate use of fluoride is still systemic. Thus, the intake of fluoridated water and foods prepared with fluoridated salt are methods that cause dental fluorosis. Considering that there is a linear relationship between dose $(\mathrm{mg} \mathrm{F} / \mathrm{kg} /$ day) and prevalence of dental fluorosis ${ }^{20}$, not only fluoride concentration in these methods must be controlled, but also all other sources of exposure must be known and avoided.

Fluoride concentration in drinking water, established 50 years ago based on means of maximum temperatures of air, is not appropriate to non-EME countries with tropical and dry climate ${ }^{58}$. Therefore, researches on the determination of the dose to which children are submitted in these areas are recommended so an appropriate exposure can be reached. Another aspect that has not been studied is the fluoride dose to which children are submitted during the various seasons of the year. The optimum concentration is normally established independently if the country or its regions have well defined seasons or not. So, for example in Brazil, the optimum fluoride concentration in water for the southeast or north region is $0.7 \mathrm{ppm}$. Nevertheless, while in São Paulo there are four seasons per year, in Belem ony two can be distinguished. The same is true in the state of São Paulo where 0.7 ppm is considered optimum for either Piracicaba or Santos, which is located on the coast. Thus, data from a pilot study ${ }^{31}$ shows that the dose to which children aged 2-3 years old are submitted in Piracicaba, SP, presents 30\% variation $(p<0.05)$ among seasons of the year (Table 11); the final study showed that during the "hot seasons" the children are subjected to a $20 \%$ higher dose than during the "cold seasons" 32 .

Considering that for each increase of $0.01 \mathrm{mg} \mathrm{F} / \mathrm{Kg}$ body weight in the dose, the increase in dental fluorosis community index value would be 0.2 , this may have a clinical significance mainly during summer and particularly in countries or regions with only two seasons during the year ("rainy and dry season").

In relation to fluoridated salt, the calculation of concentration for an appropriate exposure considers the average total consumption of a country. Considering the differences in feeding habits within a country, the exposition may not be adequate for everybody. The concentration has been established based on data from salt consumption and assessed by urinary excretion when adjustments are performed. Although the results of caries reduction by fluoridated salt have been reported, it is unknown whether or not the exposure is appropriate related to dental fluorosis. If the urinary excretion were the same as that observed from the ingestion of fluoridated water in an appropriate concentration for that region, the same dental fluorosis would be expected. On the other hand, ways to predict the exposure to fluoride by fluoridated salt must be researched in order to make it appropriate in terms of risks/benefits. Considering the concern about sodium ingestion, the trend is a reduction of salt consumption and the appropriate exposure related to benefits should be evaluated.

When a country opts for fluoridated water or fluoridated salt as public health measure to control caries, its population will consume fluoride with the risk of fluorosis in a clinically acceptable level. In this way, other sources of fluoride ingestion will increase the prevalence and severity of dental fluorosis and must

TABLE 11- Dose (mg F/Kg body weight/day) from diet (food $+\mathrm{H}_{2} \mathrm{O} \mathrm{F}$ ) in two seasons

\section{SEASONS OF THE YEAR $\quad \mathrm{mg} \mathrm{F} / \mathrm{Kg}$}

FALL $0.037 \pm 0.006 \mathrm{~A}$

WINTER $0.025 \pm 0.004 \mathrm{~B}$ 
be avoided. These sources may be natural or industrialized products. In nature, the main source of fluoride is tea and it is difficult to suggest changes when its consumption by children is related to cultural habits. Although the consumption of natural tea by children in not a habit in all non-EME countries, its industrialization makes it attractive. Table 12 shows that there is a significant amount of fluoride per can/box in industrialized teas sold in Brazil in terms of daily dose for a $12-\mathrm{kg}$ child $^{27}$.

Another natural source, which can contribute to a higher fluoride exposure, is mineral water, whose increase in consumption is observed worldwide. This is particularly important in countries that present fluoride in subterranean water. In Brazil, concentrations up to $4.4 \mathrm{ppm} F$ were found in more than 104 samples analyzed ${ }^{55}$. From the point of view of appropriate exposure, one glass of this water/day would be the limit dose for a children weighing $10 \mathrm{Kg}$ in terms of a clinically acceptable fluorosis $(0.07 \mathrm{mg} \mathrm{F} / \mathrm{Kg}$ body weight/day). In $10 \%$ of the samples an optimum concentration was observed, which would not lead to a higher fluoride exposure if fluoridated water is used. Nevertheless, there would be an overdose if fluoridated salt were used simultaneously or fluoride supplements were prescribed.

At first one could think that the possibility of a higher fluoride exposure by industrialized products is remote in non-EME countries. Nevertheless, if we are thinking in the future, measures must be taken now for regularization of these products. For example in Brazil, measures have already been taken in relation to mineral waters, but nothing was done in relation to other products on the market. Thus, high concentrations of total fluoride in infant food containing soy (up to 3.87 $\mu \mathrm{g} / \mathrm{g}$ ) were found in products sold in Brazil ${ }^{21}$. If all this fluoride is available, there will be an inappropriate exposure to fluoride. The amount of soluble fluoride in

TABLE 12- Fluoride concentration (ppm) in manufactured teas and amount (mg) per unit consumed, Piracicaba, SP, Brazil, 1999

\begin{tabular}{lll}
\hline TEA & ppm F & mg F / unit \\
\hline $\begin{array}{l}\text { LIPTON } \\
\text { (Peach-Lemon) }\end{array}$ & $0.44 \pm 0.04$ & $0.15 \pm 0.01$ \\
$\begin{array}{l}\text { PARMALAT } \\
\text { (Peach-Lemon-Apple) }\end{array}$ & $0.56 \pm 0.10$ & $0.11 \pm 0.02$ \\
REAL (Mate) & 0.54 & \\
LEÃO (Mate) & $0.04 \pm 0.01$ & $0.02 \pm 0.007$ \\
LEÃO (Peach-Lemon) & $4.13 \pm 1.19$ & $1.40 \pm 0.40$ \\
\hline
\end{tabular}

$\mathrm{HCl} 0.01 \mathrm{M}$ ("artificial gastric juice") can be determined, which is an indicator of the proportion of fluoride absorbed when calcium is present ${ }^{22}$.

Another question in non-EME countries is the exposition to fluoride from unknown sources. In every country or regions there is a typical food consumed daily. The quantity of fluoride ingested per meal should be evaluated. Although tea (Camellia sinensis) is the only known vegetable that concentrates fluoride, the widespread use of fertilizers and high concentration of fluoride in water and soil can increase its intake from rice, beans and other foods.

In summary, when a systemic method is used in a community, all other sources of fluoride exposure must be controlled in terms of risk in relation to dental fluorosis. In this aspect, the use of fluoridated toothpaste is a reality in some non-EME countries at present and will increase in the future in others for several reasons. Considering that a child, depending on the age, ingests involuntarily almost $90 \%$ of dentifrice per brushing, she may be exposed to an inappropriate amount of fluoride. We know that the use and amount of fluoridated dentifrice before three years old is related to an increase in prevalence of dental fluorosis ${ }^{42}$. Nevertheless, we do not know the best measures that should be taken for an appropriate exposure not only to raise safety but at the same time to guarantee the benefit. Would these measures be appropriate for regions containing fluoridated water or salt?

1. Non-fluoridated dentifrice for children. It would be suggested for children with low risk or caries activity. On the other hand, it would be doubtful in terms of population. In addition, $\mathrm{NaF} 0.02 \%$ using cotton swab has been suggested in Brazil for very young children for safety instead of fluoridated toothpaste ${ }^{56}$. However, an in vitro study showed that this procedure is very few effective in inhibiting the demineralization of enamel from primary teeth';

2. Dentifrice with low fluoride concentration. At first it seems to be an elementary solution to decrease the risk of dental fluorosis, considering that dentifrice contributes to $50-60 \%$ of the dose to which a child is submitted. Even though a dentifrice with $550 \mathrm{ppm} F$ decreases the mean exposure of children at compatible doses with dental fluorosis, this would not solve the individual problems of children who use a sizeable amount of dentifrice and are submitted to a daily dose of $0.18 \mathrm{mg} \mathrm{F} / \mathrm{Kg}^{44}$. In addition a dentifrice with 550 ppm needs to be evaluated to confirm if this concentration is an appropriate exposure in terms of benefit considering caries prevalence of the population;

4- Warning to use a small amount of dentifrice per brushing. Considering that there is a correlation between 
the amount of dentifrice used by children and the fluoride dose to which they are submitted ${ }^{44}$, this observation seems to be an alternative. Nevertheless, studies must be done in order to try to persuade the parents and the children to change their behavior. However, the major contribution can be offered by industry presenting educative advertisement in terms of appropriate fluoride exposure;

5- Reduce the concentration of fluoride in water and salt. At first it may seem an absurd alternative ${ }^{29}$. Nevertheless, considering that a child brushing her teeth ingests enough fluoride, the concentration of fluoride in water or salt may be reduced to a lower exposure in relation to risk. This question must be discussed because when considering the relative contribution to the risk of dental fluorosis between fluoridated water and toothpaste, we should remember that there always were public oppositions to water fluoridation ${ }^{40}$. On the other hand, considering the attributes of equity and ubiquity of use of community water fluoridation and particularly in non-EME countries, this question could be rejected. However, we must be prepared for the future because there is not opposition in the population for the use of toothpaste. The challenge will be to show the continuing caries-preventive effect of community systemic methods for all population.

The use of supplements must be questioned even in a country without fluoridated water or salt because when a child brushes her teeth there is a topical and systemic fluoride exposure ${ }^{12}$. The lobby from pharmaceutical industries is very strong and present facts will avoid an inadequate fluoride exposure in the future. In Brazil, 114 medicines containing fluoride are produced by 65 laboratories. They are over-the-counter medicines prescribed in area with fluoridated water ${ }^{5}$ and the dosage followed by clinicians will submit children up to three years old to an overdose even in an area without fluoridated water ${ }^{26}$. Thus, the use of these products will lead to an inappropriate fluoride exposure and its indication for children must be questioned even when the water does not contain fluoride.

In this discussion about appropriate fluoride exposure, the factor risk was discussed and can be anticipated particularly in relation to dental fluorosis because there is a linear relationship between doseeffect $^{20}$. Nevertheless, in relation to benefit, what would be the appropriate exposure to control caries? Unfortunately, there is no dose-response effect that can be used to eliminate the disease, because it is multifactorial and the main effect of fluoride is to interfere with caries progression. Thus, as the effect is local it depends on concentration and not on the dose. This is true even for systemic methods in which an optimum concentration is used, not in terms of benefit but mainly in terms of risk. On the other side, as there is no linear relationship between fluoride concentration of a topical method and a concomitant caries reduction, a combination of methods is an alternative in a population with high caries activity. Thus, it is possible to reduce caries prevalence from high to moderate by exposing a population to fluoridated water. A higher caries reduction is possible if weekly fluoride rinse is used $^{37}$. Nevertheless, a reduction in dental caries prevalence to low or very low values is only observed when education for oral health is introduced with toothbrushing using fluoridated dentifrice. This fact has been proved even in non-EME countries and the Brazilian experience is an example. The public water from the city of Santos, SP, is fluoridated since 1975. After 14 years of water fluoridation, DMFT ${ }_{12}$ was reduced by $43 \%$ (Table 8 ), but caries prevalence was still high. Nevertheless, only 6 years after the implementation of a health oral program called "Santos de Sorriso Novo", the DMFT ${ }_{12}$ reached 1.7, showing a reduction of $67 \%$ in dental caries prevalence ${ }^{24}$. In this program the students received gratuitously toothbrush and fluoridated dentifrice supported by an educational program of oral hygiene. Thus, we know that fluoride works when the use and exposure are appropriate. The disease was reduced and the health improved, because 62.5 and $45.4 \%$ of children, respectively, 5 and 12 years old were caries free. At the same time, $15 \%$ of children aged 5 years old and $20 \%$, aged 12 years old had from 4 to 15 teeth with caries experience ${ }^{24}$.

However, what don't we know at the present time in terms of future?

1- When to stop using combinations of methods. Caries reduction is a reality in Brazil, but several programs continue using fluoridated rinses and some use professional topical application. Wouldn't daily toothbrushing with fluoridated dentifrice associated with fluoridated water be an appropriate exposure in terms of benefit? Couldn't fluoridated rinses and particularly professional fluoride application be directed to those 15 and $20 \%$ of children respectively at 5 and 12 years old, who present 4 to 15 teeth attacked by caries?;

2- How to predict this group of children with high caries experience for an attention according to the needs?;

3- Would the exposure of these children to more fluoride be the most appropriate solution or should we interfere with the oral microbiota?;

4- This high caries experience in $15-20 \%$ of the children would be only a social problem?;

These data from non-EME country showed that the 
exposure to fluoride was able to reduce the severity of dental caries. However, a low caries prevalence was only reached when programs for oral health were implemented or dental plaque was disrupted regularly by brushing. So, for non-EME countries with low caries prevalence the emphasis for a good oral hygiene with a minimum fluoride exposure makes sens $\mathrm{e}^{34}$. If feasible, fluoride toothpaste would be the rational indication, because the implementation of habits for oral hygiene before the widespread consumption of sucrose can control caries progression with low exposure to fluoride. In addition, the mistake made in EME countries and in some non-EME countries must not be repeated. After generations have been destroyed by caries disease followed by a widespread exposure to fluoride, we are now discussing the most appropriate exposure to fluoride considering risks/benefits.

These questions are relevant because, due to the importance that fluoride has received, it has been used in Dentistry for almost a century. The determination of appropriate fluoride exposure in non-EME countries in the future is important now because it will enable:

1. Its use with safety in terms of dental fluorosis, identifying the factors of risk;

2. Its rational use in terms of dental caries control, identifying not only what and when to use, but mainly to have wisdom when to stop using.

\section{Key Research Questions}

1- Need of epidemiological surveys of caries and dental fluorosis in national level in non-EME countries;

2- Would $0.07 \mathrm{mg} \mathrm{F} / \mathrm{Kg}$ body weight/day be the limit dose for a clinically acceptable fluorosis?;

3- Determine multiple sources of fluoride ingestion and its contribution to the dose for a clinically acceptable dental fluorosis;

4- Reevaluate the determination of optimum fluoride concentration in water for tropical countries;

5- Evaluate the need of fluoride supplements for children who already use fluoridated dentifrices;

6- Hydrogeologic survey of fluoride in subterranean water and its effect in the environment;

7- Determine the factors which have contributed to low caries prevalence in some countries without fluoride use;

8- Determine the appropriate fluoride exposure after dental caries has been reduced from a very high or high level to a low one;

9- Determine the factors responsible for caries in $15-20 \%$ of children, who are submitted to appropriate fluoride exposure but still show very high caries activity;

10- How to control caries in a group of children
(15-20\%), who are submitted to appropriate fluoride exposure, but still show very high caries activity;

11-Determine the appropriate exposure to fluoride for very young children before they start to brush their teeth;

12- Determine the appropriate exposure to fluoride by children using toothpaste, considering risk/ benefit.

\section{RESUMO}

Uma exposição apropriada ao fluoreto é aquela capaz de interferir com o desenvolvimento de cárie dental (benefício) sem grandes preocupações com fluorose dental (riscos). Esta condição em termos de indivíduo parece factível levando ao uso racional do fluoreto. Entrentanto, em se tratando de população e particularmente países non-EME, o método mais adequado de usar fluoreto vai depender de cada nação. Por outro lado, é imprescindível que haja uma política nacional de um método coletivo para controlar cárie como integrante do sistema de saúde de cada país. A escolha entre dentifrício fluoretado ou água fluoretada e a opção por sal vai depender da sua aplicabilidade a cada país. Ao mesmo tempo, é importante que para cada país seja avaliada não só a exposição apropriada do método coletivo de usar fluoreto, assim como a associação com outros métodos e meios em termos de riscos-benefícios. A determinação da exposição apropriada a fluoreto nos países non-EME no futuro dependerá da análise crítica de como ele tem sido usado no presente. Dados disponíveis têm mostrado que alguns países non-EME têm inclusive conseguido reverter a situação dramática de cárie de sua população, mas em outros a experiência de cárie continua dramática. Entretanto, em outros países não tem ocorrido um aumento da prevalência de cárie que se esperaria, mas fluorose endêmica é uma preocupação. Os desafios para países non-EME são imensos e para problemas distintos não existem as mesmas soluções.

UNITERMOS: Flúor; Fluorose dental; Cárie dental, riscos/benefícios.

\section{REFERENCES}

1- Abdennebi EH, Fandi R, Lamnaouer D. Human fluorosis in Morocco: analytical and clinical investigation. Vet Hum Toxicol 1995; 37:465-8.

2- Barmes D. Determining optimal levels of fluoride in drinking water for hot dry climates - a case study in Sri Lanka. Community Dent Oral Epidemiol 1993; 21:245-6. 
3- Basting RT, Pereira AC, Meneghim MC. Evaluation of dental caries prevalence in students from Piracicaba, SP, Brazil, after 25 years of fluoridation of the public water supply. Rev Odontol Univ São Paulo 1997; 11:287-92.

4- Bezerra de Menezes LA, Sousa MLR, Rodrigues LKA, Cury JA. Autopercepção da fluorose pela exposição a flúor pela água e dentifrício. Rev Saúde Pública 2002; 36:752-4.

5- Borges GD, Villena RS, Fonoff NR, Trindade CP. Evaluation of the recommendations for use of topical and systemic fluorides by Brazilian dentists. J Dent Res 1997 [abstract n. 12]. 76(sp issue): 15 .

6- Bratthall D, Petersson G, Sundberg G. Reasons for the caries decline. What do the experts believe. Eur J Oral Sci 1996; 104:41622.

7- Brouwer ID, Dirks OB, De Bruin A, Hautvast JG. Unsuitability of World Health Organisation guidelines for fluoride concentrations in drinking water in Senegal. Lancet 1988; 30:2235 .

8- Burt BA. The changing patterns of systemic fluoride intake. J Dent Res 1992; 71:1228-37.

9- Chedid SJ, Cury JA. An evaluation of fluoride dentifrice or $0.02 \% \mathrm{NaF}$ solution on caries development in deciduous teeth using a pH-cycling model [abstract n. 528]. J Dent Res 1999; 78(sp issue): 171

10- Chedid SJ, Cury JA. Evaluation of the use of fluoridated dentifrice by children and the aesthetic perception of the parents in relation to the level of dental fluorosis. Anais da 16. Reunião da Sociedade Brasilira de Pesquisa Odontológica - SBPqO; 1999 set. 8-11; Águas de São Pedro (SP). São Paulo: SBPqO,1999.

11- Cirino SM, Scantlebury S. Dental caries in developing countries. Preventive and restorative approaches to treatment. N Y State Dent J 1998; 64:32-9.

12- Cury JA. Fluoride metabolism after intake of dentifrices. Rev Gaucha Odont 1986; 34:425-7.

13- Cury JA. Fluoridated dentifrice in the Brazilian market and its potential as preventive method. Brazilian Association for Preventive Dentistry - a special publication; 1990.

14- Cury JA. Evaluation of the fluoridated dentifrices sold in Brazil [abstract n. 213]. J Dent Res 1990; 69(sp issue):373.

15- Cury JA. Evaluation of the program of salt fluoridation in Brazil - A technical report. Ministry of Health of Brazil - Oral Health Department, August 26, 1991.

16- Cury JA. Fluoride use and the control of caries as a disease. In: Baratieri LN et al., editors. Restorative dentistry - principles and perspectives. São Paulo, SP, Brazil. Editora Santos; 2001. $33-68$.

17- Cury JA, Rebello MAB, Del Bel Cury AA, Derbyshire MTVC, Tabchoury CPM. Biochemical composition and cariogenicity of dental plaque formed in the presence of sucrose or glucose and fructose. Caries Res 2000; 34:491-7.
18- Ellwood RP, Cortea DF, O'Mullane DM. A photographic study of developmental defects of enamel in Brazilian school children. Int Dent J 1996; 46:69-75.

19- Fejerskov O, Baelum V, Luan WM, Manji F. Caries prevalence in Africa and the People's Republic of China. Int Dent J 1994; 44:425-33.

20- Fejerskov O, Baelum V, Richards A. Dose-response and dental fluorosis. In: Fejerskov O, Ekstrand J, Burt BA. Fluoride in Dentistry. $2^{\text {nd }}$. ed. Copenhagen: Munksgaard; 1996. Chap. 9.

21- Fernandes DRM, Tabchoury CM, Cury JA. Fluoride concentration in infant foods and risk of dental fluorosis [abstract n. 1505]. J Dent Res 2001; 80 (sp issue):224.

22- Fernandes LMAG, Cury JA. Metabolic evaluation of prenatal fluoride supplements. Rev Bras Med 1993;50:1546-54. (In Portuguese)

23- Fraysse C, Bilbeissi MW, Mitre D, Kerebel B. The role of tea consumption in dental fluorosis in Jordan. Bull Group Int Rech Sci Stomatol Odontol 1989; 32:39-46.

24- FSH-USP/SEHIG-Santos - A technical report from Public Health Faculty, USP, 1995.

25- Gomes Salgado J. Control and continuity of the iodized and fluoridated domestic salt in Costa Rica. Fluoracion dia 1991; 1:236. (In Spanish)

26- Hanan SA, Rebelo MAB, Cury JA. Evaluation of the fluoride supplements prescription in Manaus and analysis of Brazilian market products [abstract n. A78]. J Dent Res 1999;78:970.

27- Hayacibara MF, Queiroz CS, Tabchoury CPM, Cury JA. Fluoride and aluminum in teas, tea-based beverages and herbalteas. Rev Saúde Pública, accepted (2003).

28- Health Ministry of Brazil. DMFT in Brazilian children 12year old. Brazilian Dental Association News 1996 Nov/Dec.

29- Horowitz HS. Appropriate uses of fluoride: considerations for the '90s. Introductory paper. J Publ Hlth Dent 1991; 51:20-2.

30- Ibrahim YE, Affan AA, Bjorvatn K. Prevalence of dental fluorosis in Sudanese children from two villages with 0.25 and 2.56 ppm fluoride in the drinking water. Int J Paediat Dent 1995; 5:223-9.

31- Lima YBO, Cury JA. Estimation of total fluoride intake by children during different seasons, in a region with fluoridated water [abstract n. A-085]. J Dent Res 2000; 79:1079 .

32- Lima YBO, Cury JA. Seasonal variation of fluoride intake by children in a subtropical region. Caries Res 2003 /In press/.

33- Manfredini MA. A technical report about oral health in Santos, SP, Brazil Department of Hygiene and Health - Oral Health Group 1995. (In Portuguese)

34- Manji F, Fejerskov O. Dental caries in developing countries in relation to the appropriate use of fluoride. J Dent Res 1990; 69(sp issue):733-41. 
35- Maupome Carvantes G, Jaramillo Lanchero RD, Andrade Delgado LC, Juarez Reyes PL, Lopez Perez R, Sanchez Navarro W, et al. Fluoride content of table salt in Mexico City. Bol Oficina Sanit Panam 1995; 119:195-201. (In Spanish)

36- Meyer-Lueckel H, Satzinger T, Kielbassa AM. Caries prevalence among 6- to 16-year-old students in Jamaica 12 years after the introduction of salt fluoridation. Caries Res 2002; 36:1703.

37- Moreira BH, Guimaraes LO, Vieira S, Piedade EF. Fluoride mouthwashes in combination with fluoridation of the public water supply for the prevention of dental caries. Rev Assoc Paul Cir Dent 1981; 35:296-301.

38- Mosha HJ, Scheutz F. Dental caries in the permanent dentition of schoolchildren in Dar es Salaam in 1979, 1983 and 1989. Community Dent Oral Epidemiol 1992; 20:381-2.

39- Neder C; Manfredini MA. About the opportunities of fluoridation: The modernity of delay. Saude em Debate 1991; 32:72-4. (In Portuguese)

40- Newbrun E. The fluoridation war: A scientific dispute or a religious argument? J Public Health Dent 1996; 56:246-52.

41- Nobre dos Santos M, Melo dos Santos L, Francisco SB, Cury JA. Relationship among dental plaque composition, daily sugar exposure and caries in the primary dentition. Caries Res 2002; $36: 347-52$

42- Osuji OO, Leake JL, Chipman ML, Nikiforuk G, Locker D, Levine N. Risk factors for dental fluorosis in a fluoridated community. J Dent Res 1988; 67:1488-92.

43- Paiva SM, Barros Filho MA. Endemic fluorosis in CocalUrussanga, SC, Brazil. Revista de Odontopediatria - Atualização Clínica 1993; 1:5-15. (In Portuguese)

44- Paiva SM, Lima YBO, Cury JA. Fluoride intake by Brazilian children from two communities with fluoridated water. Community Dent Oral Epidemiol 2003; 31/In press/

45- Pereira AC, da Cunha FL, Meneghim MC, Werner CW. Dental caries and fluorosis prevalence study in a nonfluoridated Brazilian community: trend analysis and toothpaste association. ASDC J Dent Child 2000; 67:132-5.

46- Pereira AC, Mialhe FL, Bianchini FLC, Meneghim MC. Prevalence of caries and dental fluorosis in scholars from cities with different fluoride concentrations in drinking water. Rev Bras Odont Saúde Coletiva 2001; 2:34-9. (In Portuguese)

47- Pereira AC, Moreira BH. Analysis of three dental fluorosis indexes used in epidemiologic trials. Braz Dent J 1999; 10:29-37.

48- Rodriguez Mendez G, Sanjurjo Gomez V, Fernandez Brito M, Delgado Reyes N. Morbidity of dental caries and inflammatory periodontal disease in an area with artificial fluoridation of the drinking water. Rev Cubana Estomatol 1985; 22:125-37.

49- Salas M. Fluoridated salt. CEDROS Network 1995.
50- Salas Pereira MT. Dental caries vs. fluorosis: a study in 5 and 7 year old children from Tierra Blanca and Llano Grande, Cartago, Costa Rica. Fluoracion dia 1991; 1:27-30. (In Spanish)

51- Sampaio FC. Prevalence of dental caries and fluorosis in cities of Paraiba with residuals levels of fluoride in water supply. CCS 1993; 12:11-9. (In Portuguese)

52- Silva MFA. Doubts about salt fluoridation in Brazil. Rev Gaucha Odont 1991; 39:306-8. (In Portuguese)

53- Simoni Gil PS, Amadio Rodrigues AM, Cury JA, Guimarães LOC, Moreira BW. Fluoridation of the salt. III - A metabolic study. Rev Gaúcha Odont 1989; 37:271-3. (In Portuguese)

54- Villa AE, Guerrero S, Villalobos J. Estimation of optimal concentration of fluoride in drinking water under conditions prevailing in Chile. Community Dent Oral Epidemiol 1998; $26: 249-55$

55- Villena RS, Borges DG, Cury JA. Evaluation of fluoride content of bottled drinking waters in Brazil. Rev Saude Publica 1996; 30:512-8. (In Portuguese)

56- Walter LRF. Dentistry for toddler (In Portuguese). São Paulo: Artes Médicas; 1996. p.216.

57- Wang LF, Huang JZ. Outline of control practice of endemic fluorosis in China. Soc Sci Med 1995; 41:1191-5.

58- WHO. Fluoride and oral health. WHO Technical Report Series. 1994; 846:16-19.

59- World Health Organization (WHO). Global Oral Bank Data, Internet, April 2, 1999.

60- Yoder KM, Mabelya L, Robison VA, Dunipace AJ, Brizendine EJ, Stookey GK. Severe dental fluorosis in a Tanzanian population consuming water with negligible fluoride concentration. Community Dent Oral Epidemiol 1998; 26:382-93.

Full address of corresponding author:

Jaime A. Cury

Av. Limeira, 901, Piracicaba, SP

13414-903, Brazil

phone 55-19-3412-5302; fax 55-19-3412-5218

e-mail: jcury@fop.unicamp.br 